\title{
TELEOST LUTEINIZING HORMONE-RELEASING HORMONE: ACTION ON BULLFROG SYMPATHETIC GANGLIA IS CONSISTENT WITH ROLE AS NEUROTRANSMITTER ${ }^{1}$
}

\author{
STEPHEN W. JONES, ${ }^{* 2}$ PAUL R. ADAMS,* MICHAEL J. BROWNSTEIN, $\ddagger$ and JEAN E. RIVIER \\ *Department of Neurobiology and Behavior, State University of New York at Stony Brook, Stony Brook, New York 11794, łUnit \\ on Neuroendocrinology, Laboratory of Clinical Science, National Institute of Mental Health, Bethesda, Maryland 20205, und \\ $\S$ Peptide Biology Laboratory, The Salk Institute for Biological Studies, La Jolla, California 92037
}

Received April 13, 1983; Revised August 22, 1983; Accepted September 21, 1983

\begin{abstract}
Bullfrog sympathetic ganglion neurons have a "late, slow" excitatory postsynaptic potential (EPSP) that is mediated by a peptide similar to mammalian luteinizing hormone-releasing hormone (M-LHRH) (Jan, Y. N., L. Y. Jan, and S. W. Kuffler (1979) Proc. Natl. Acad. Sci. U. S. A. 76 : 1501-1505). On biochemical evidence (Eiden, L. E., E. Loumaye, N. Sherwood, and R. L. Eskay (1982) Peptides 3: 323-327) the endogenous LHRH-like peptide in the ganglion may be identical to teleost LHRH (T-LHRH; [Trp ${ }^{7}$,Leu $\left.{ }^{8}\right]$ M-LHRH) (Sherwood, N., L. Eiden, M. Brownstein, J. Speiss, J. Rivier, and W. Vale (1983) Proc. Natl. Acad. Sci. U. S. A. 80: 2794-2798). We have found that T-LHRH acts qualitatively like M-LHRH on bullfrog ganglion cells, but it is quantitatively more potent. As for M-LHRH, the primary action of T-LHRH under single-electrode voltage clamp is to inhibit the M-current, a voltage-dependent potassium current that is active in the region between rest and threshold in these cells. The M-current is also inhibited during the late, slow EPSP. Both T-LHRH and the late, slow EPSP can also induce an additional inward current, associated with an increased conductance, in some cells. An LHRH antagonist is effective against both T-LHRH and the late, slow EPSP. These results are consistent with a role for T-LHRH as the natural transmitter for the late, slow EPSP in bullfrog sympathetic ganglia.
\end{abstract}

There is increasing evidence that a wide variety of peptides, several of which were originally discovered as hormones, are present in many locations in the nervous system (Hökfelt et al., 1980). This work has progressed rapidly, largely due to the use of powerful immunological techniques for the biochemical measurement and anatomical localization of peptides. However, the wealth of information available on the presence of peptides in the nervous system has not been matched by information on the physiological actions of neuropeptides at the cellular level (reviewed by Kelly, 1982; North and Egan, 1982). To demonstrate that a substance is a neurotransmitter, it is of course necessary to show that it acts appropriately as well as to show that it is present.

One exception to this rule is the bullfrog sympathetic ganglion, where there is convincing evidence not only that a peptide closely related to mammalian luteinizing hormone-releasing hormone (M-LHRH) is present, but

\footnotetext{
${ }^{1}$ This work was supported by National Institutes of Health Grant NS 18579 to P. R. A., a National Institutes of Health postdoctoral fellowship to S. W. J., and the Klingenstein Fund.

${ }^{2}$ To whom correspondence should be addressed.
}

also that it is released upon physiological stimulation, and that it acts to produce a slow depolarization of the principal cells of the ganglion (Jan et al., 1979, 1980; Kuffler, 1980; Jan and Jan, 1982). In addition, Adams and Brown (1980) have reported that the observed depolarization is associated with inhibition of the M-current, a specific voltage-dependent current carried by potassium (Adams et al., 1982a). This system is one of the most thoroughly characterized examples of peptidergic transmission in the nervous system.

However, some important questions remain. First, the M-LHRH-like peptide present in the ganglion is chromatographically and immunologically distinguishable from M-LHRH (Eiden and Eskay, 1980). A clue to the identity of the natural transmitter for the late, slow EPSP has been provided by the observation that the MLHRH-like peptide of bullfrog ganglia is indistinguishable from the LHRH of teleost fish (T-LHRH) by different chromatography systems and different antisera (Eiden et al., 1982). The amino acid sequence of TLHRH has recently been found to be $\left[\operatorname{Trp}^{7}, \mathrm{Leu}^{8}\right] \mathrm{M}$ LHRH (Fig. 1; Sherwood et al., 1983). We report here that T-LHRH acts qualitatively like M-LHRH on bull- 


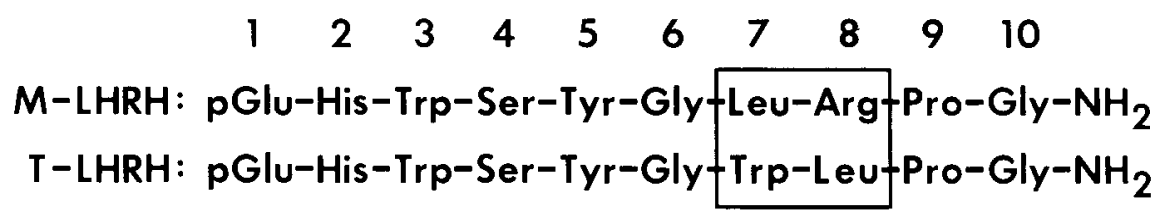

Figure 1. Primary structure of mammalian and teleost LHRH. The structure of T-LHRH is from Sherwood et al. (1983).

frog ganglion neurons, but that T-LHRH is considerably more potent on these cells.

Second, there are effects of M-LHRH and of the late, slow EPSP on bullfrog sympathetic ganglion neurons that cannot be explained by inhibition of the M-current (Katayama and Nishi, 1977, 1982; Jan et al., 1980; Kuffler, 1980; Sejnowski, 1982; Kuffler and Sejnowski, 1983). In particular, some (but not all) cells have been found to be depolarized by M-LHRH even at the equilibrium potential for potassium, where inhibition of the M-current would produce no effect. We have therefore investigated the issue of non-M-current effects of T-LHRH and have studied the late, slow EPSP under voltage clamp.

\section{Materials and Methods}

Principal neurons of bullfrog paravertebral ganglia were impaled with single $3 \mathrm{M} \mathrm{KCl}$-filled 10 - to 20 -megohm microelectrodes (WPI Instruments TW150F tubing pulled on a Brown-Flaming P-77 micropipette puller from Sutter Instruments), and were voltage clamped with a Dagan 8100 switched clamp system, as described (Wilson and Goldner, 1975; Adams et al., 1982b; Galvan and Adams, 1982). Most cells were clamped at $-30 \mathrm{mV}$ with steps to $-60 \mathrm{mV}$, to investigate the range in which the M-current is activated; some cells were also examined at more hyperpolarized potentials, as far as $-120 \mathrm{mV}$. In this range, the single electrode clamp gave good voltage control, except for a systematic depolarization of 1 to 4 $\mathrm{mV}$ during responses where the M-current was strongly inhibited. This error reflects the limited loop gain in single-electrode voltage clamp. Since the M-current is activated by depolarization, this would cause underestimation of M-current inhibition. We calculate, on the basis of the activation kinetics of the M-current (Adams et al., 1982a), that a depolarization from -32 to $-30 \mathrm{mV}$ with $50 \%$ inhibition of the M-current would give an apparent inhibition of $46 \%$. We have not corrected for this effect.

The usual frog Ringer's solution contained (in millimolar concentration): $\mathrm{NaCl}, 115 ; \mathrm{KCl}, 2.5 ; \mathrm{CaCl}_{2}, 2$; $\mathrm{MgCl}_{2}, 10$; Tris base, 2.5 (titrated to $\mathrm{pH} 7.2$ with $\mathrm{HCl}$ ). (The composition of this Ringer's solution was given incorrectly in Adams and Brown (1980) and Adams et al. (1982a).) M-LHRH, [D-Ala ${ }^{6}$ ]M-LHRH, and [DpGlu $\left.{ }^{1}, \mathrm{D}-\mathrm{Phe}^{2}, \mathrm{D}-\mathrm{Trp}^{3,6}\right] \mathrm{M}$-LHRH were obtained from Peninsula Laboratories, Belmont, CA; atropine sulfate and $d$-tubocurarine chloride were obtained from Sigma Chemical Co., St. Louis, MO. T-LHRH was synthesized in the laboratory of J. Rivier.

Ganglia were treated with $1 \%$ trypsin for 5 to $10 \mathrm{~min}$ during the dissection unless noted otherwise. The ganglia were maintained in a steady flow of Ringer's solution (approximately $20 \mathrm{ml} / \mathrm{min}$ ); drugs were applied either in the bathing medium or by pressure ejection from microelectrodes using a Picospritzer II (General Valve) at 5 to $80 \mathrm{psi}$. Two types of pressure pipettes were used: either pipettes prepared as for patch-clamp recording, which had tip diameters of about $1 \mu \mathrm{m}$ and required typically 20 to $80 \mathrm{psi}$, or three-barrel pipettes broken off to 2 - to $10-\mu \mathrm{m}$ tips, which allowed the use of lower pressures.

In some preparations, the preganglionic fibers were stimulated by a suction electrode on the nerve trunk connecting the ganglia, above the 8th or 9th ganglion. The ganglia, which had not been treated with trypsin, were bathed in Ringer's solution containing $4 \mathrm{mM} \mathrm{CaCl}_{2}$ and no $\mathrm{MgCl}_{2}$ (to enhance transmitter release), $1 \mu \mathrm{M}$ atropine (to block the slow EPSP and IPSP), and $20 \mu \mathrm{M}$ $d$-tubocurarine (to reduce the fast EPSP). To produce a late, slow EPSP, the nerve was stimulated at approximately 10 times the voltage necessary to produce a fast EPSP in a B cell, to activate the high threshold C fiber input to the ganglion. To improve stability, the bath superfusion rate was slowed to approximately 2 to $5 \mathrm{ml} /$ $\min$.

A Gould 2400 chart recorder was used for all records shown. The amplitudes of the M-current relaxations were measured directly from the chart record. Often, a step from -60 to $-30 \mathrm{mV}$ produced a brief transient, consisting of a mixture of A-current (Adams et al., 1982a), clamp settling, and occasionally a reflection of an axonal anode-break spike. In such cases, the slow Mcurrent tail was extrapolated linearly back to the start of the step. A more accurate but more laborious procedure, extrapolation of a semilog plot of the tail, gave comparable estimates in the few cases tested.

\section{Results}

The most obvious and consistent effect of T-LHRH was to decrease the M-current (Fig. 2). Inhibition of the M-current by T-LHRH was reflected in (1) an inward current at $-30 \mathrm{mV}$, due to reduction in the outward potassium current normally flowing through the M-current channels at that potential (Fig. $2 A$ ), (2) a reduction in the amplitude of the slowly developing currents at the onset and offset of the hyperpolarizing pulse (Fig. $2 B$ ), (3) a reduction in the amplitude of the "instantaneous" current at the voltage step from $-30 \mathrm{mV}$ to $-60 \mathrm{mV}$, reflecting the higher ohmic resistance at $-30 \mathrm{mV}$ in $\mathrm{T}$ LHRH, and (4) the lack of effect on the steady-state current level or cell resistance at $-60 \mathrm{mV}$, where the $\mathrm{M}$ current is normally inactive. This action is qualitatively identical to that previously reported for M-LHRH (Adams and Brown, 1980). In this cell, T-LHRH was equally active from either pressure or bath application, suggesting that pressure application essentially perfused the cell 

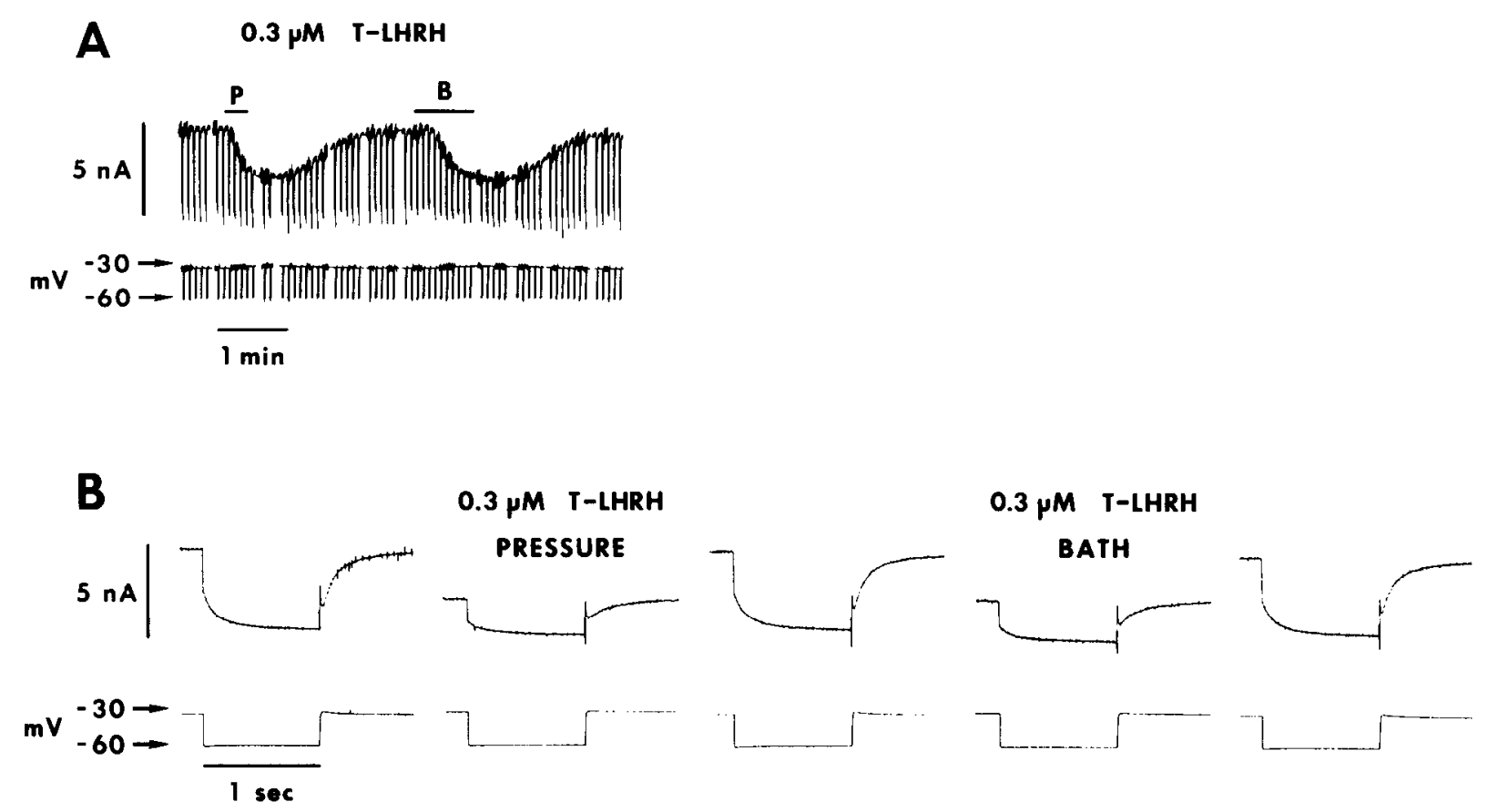

Figure 2. Inhibition of the M-current by T-LHRH. A, Current (top) and voltage (bottom) records of responses of a voltageclamped bullfrog ganglion cell to $0.3 \mu \mathrm{M}$ T-LHRH applied by pressure ejection ( 20 sec at 20 psi, at $P$ ) or in the bath (for 50 sec, at $B$ ). The cell was clamped at $-34 \mathrm{mV}$ with steps every $5 \mathrm{sec}$ to $-60 \mathrm{mV}$ for 1 sec. Gaps in the record correspond to places where the chart recorder was run 100 times faster to observe the time course of the currents flowing in response to the voltage jumps. $B$, Fast records from the same responses shown in $A$. From left to right, the records show responses to voltage steps before, $20 \mathrm{sec}$ after pressure application, $120 \mathrm{sec}$ after, $35 \mathrm{sec}$ after the end of bath application, and $105 \mathrm{sec}$ after. When a bullfrog ganglion neuron is voltage clamped near $-30 \mathrm{mV}$ and subjected to a 1-sec hyperpolarizing command to $-60 \mathrm{mV}$ (e.g., upper left record in $B$ ), there is first an "instantaneous" inward current, reflecting the resistance of the cell at $-30 \mathrm{mV}$, followed by a slowly developing inward current due to the closing of M-current channels (i.e., a decrease in the outward potassium current flowing through those channels). Upon the return to $-30 \mathrm{mV}$, there is a rapid outward current due to both the ohmic current determined by the cell's resistance at $-60 \mathrm{mV}$ (which is significantly higher than at $-30 \mathrm{mV}$ due to closure of M-channels) and to activation of a transient outward potassium current (A-current; Adams et al., 1982a). The slow outward current that follows is due to reactivation of the $\mathrm{M}$-current at $-30 \mathrm{mV}$.

with T-LHRH at the concentration present in the pipette, as others (e.g., Choi and Fischbach, 1981) have observed. However, in other cells, the pressure-applied T-LHRH appeared to be diluted before reaching the cell, and positioning of the pressure pipette was critical for some cells.

The action of T-LHRH was concentration dependent (Fig. 3). This was particularly true for any given cell, as different cells varied in sensitivity to T-LHRH (perhaps a 10 -fold variation in $I_{50}$ ), with rare unresponsive cells. T-LHRH was at least 10 -fold more potent than $\mathrm{M}$ LHRH: bath application of $0.3 \mu \mathrm{M}$ T-LHRH produced greater inhibition of the $\mathbf{M}$-current than did $3 \mu \mathrm{M} \mathbf{M}$ LHRH on seven of seven cells from three frogs. Figure 4 shows a cell in which pressure-applied $0.3 \mu \mathrm{M}$ T-LHRH was equipotent with bath-applied $3 \mu \mathrm{M}$ M-LHRH. Note also that the actions of M-LHRH and T-LHRH are not additive, suggesting that they act by a common, saturable mechanism. Bath-applied T-LHRH was slightly more potent than [D-Ala ${ }^{6}$ ]M-LHRH: $0.3 \mu \mathrm{M}$ 'T-LHRH produced $42 \pm 2 \%$ inhibition of the M-current versus $30 \pm$ $3 \%$ for $0.3 \mu \mathrm{M}$ [D-Ala $\left.{ }^{6}\right] \mathrm{M}-\mathrm{LHRH}$, based on 8 to 16 cells from three frogs.

The action of T-LHRH on the M-current was antagonized by [D-pGlu $\left.{ }^{1}, \mathrm{D}-\mathrm{Phe}^{2}, \mathrm{D}-\mathrm{Trp}^{3,6}\right] \mathrm{M}-\mathrm{LHRH}$, an an- tagonist of M-LHRH receptors (Rivier and Vale, 1978), which also has been reported to block the depolarizing action of M-LHRH on bullfrog sympathetic ganglion cells (Jan et al., 1980). Figure 5 shows that the antagonist accelerated recovery of the $\mathrm{M}$-current following $\mathrm{T}$ LHRH application and reduced the response to a subsequent application of T-LHRH. This suggests that MLHRH and T-LHRH act on the same receptor in bullfrog ganglia.

In some cells, an inward current was evoked by $\mathrm{T}$ LHRH even at $-60 \mathrm{mV}$, where the M-current should be turned off. This was observed particularly often for relatively long applications or high concentrations of TLHRH, and where large fractions of the M-current were inhibited. Figure 4 shows that brief applications of $\mathrm{M}$ LHRH and T-LHRH produced predominantly M-current inhibition, but longer applications also gave obvious inward current at $-60 \mathrm{mV}$. Another typical characteristic of such responses is that the development of the inward current at $-60 \mathrm{mV}$ lagged behind the effects at $-30 \mathrm{mV}$, and the recovery was often slower at $-60 \mathrm{mV}$ as well.

To investigate the question of non-M-current effects of T-LHRH more systematically, we clamped cells at -60 to $-70 \mathrm{mV}$, with alternating steps to more positive potentials (to activate M-current) and to more negative 

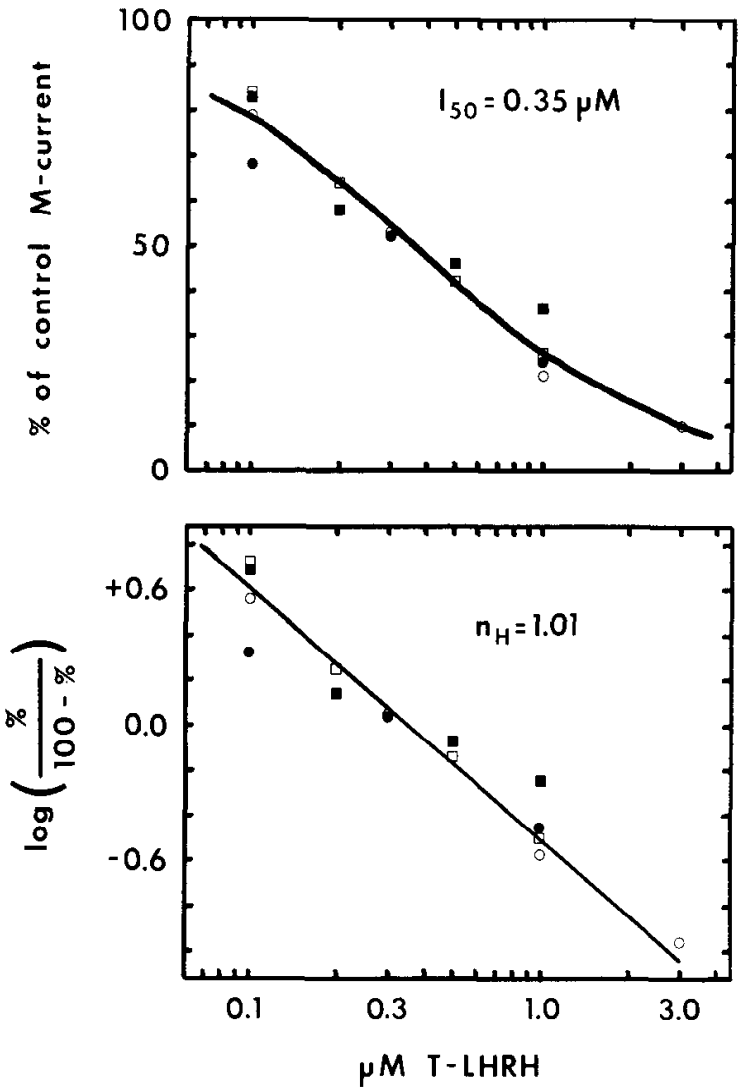

Figure 3. Dose response curves for inhibition of the $\mathrm{M}$ current by T-LHRH. Cumulative dose response curves were obtained for bath-applied T-LHRH in four cells in ganglia from two frogs. That is, the cell was exposed sequentially to three or four increasing concentrations of T-LHRH, for approximately $1 \mathrm{~min}$ at each concentration. Each symbol represents a single cell. For each cell, inhibition of the M-current was calculated from the average of values from measurement of the amplitude of the slow deactivation of the M-current (on the step from $-30 \mathrm{mV}$ to $-60 \mathrm{mV}$ ) and from the reactivation (on return to $-30 \mathrm{mV}$ ). Top, logarithmic plot; bottom, Hill plot. The lines drawn, and values for $I_{50}(0.35 \pm 0.06 \mu \mathrm{M})$ and Hill coefficient $\left(n_{\mathrm{H}}=1.01 \pm 0.07\right)$ were estimated by linear regressions on the Hill plot.

potentials (to examine the effects of T-LHRH in the absence of M-current). Figure 6 shows two such cells, one of which showed only inhibition of the M-current, and one where an additional inward current developed. That current was associated with a slight increase in the conductance of the cell (about 10\% for the cell illustrated), as determined from a slight increase in the ohmic current at the step from -70 to $-100 \mathrm{mV}$. This additional inward current appeared immediately upon the voltage step, unlike the slowly relaxing $\mathbf{M}$-current.

The presence of an additional inward current induced by T-LHRH was not limited to cells that (as the one in Fig. $6 B$ ) had not been treated with trypsin. Figure 7 shows current-voltage curves for two cells, one (Fig. 7A) from the same ganglion as the cell of Figure $6 B$ that nevertheless shows only inhibition of the M-current, another (from a trypsinized ganglion) that did show an additional inward current. Figure $7 C$ shows the time course of the steady-state current levels at different potentials for the same response as Figure $7 B$, to illustrate that the $\mathrm{M}$-current inhibition tended to precede the development of the additional inward current, and that $\mathrm{M}$-current recovered more rapidly than did the additional current.

M-LHRH also induced an additional inward current in some cells, and Figure 8 shows that this effect is also reversed by the LHRH antagonist. This is further evidence for the specificity of the increased conductance effect. During prolonged bath application of a high concentration $(20 \mu \mathrm{M})$ of M-LHRH, a pressure application of $100 \mu \mathrm{M}$ [D-pGlu ${ }^{1}, \mathrm{D}-\mathrm{Phe}^{2}, \mathrm{D}^{\mathrm{T}} \mathrm{Trp}^{3,6}$ ]M-LHRH (plus 20 $\mu \mathrm{M}$ M-LHRH, to hold the M-LHRH concentration constant regardless of the extent of mixing of bath and pressure-applied drug) caused a transient recovery of both the M-current (see fast records) and the additional inward current (reflected in changes in steady-state current at $-60 \mathrm{mV}$, and in reduction of the fast ohmic current step upon repolarization from -60 to $-30 \mathrm{mV}$ ). The rapid return of the inward currents after the end of the antagonist application suggests that the antagonist is rather rapidly reversible in these cells, at least in the presence of a high concentration of agonist.

If T-LHRH is the transmitter for the late, slow EPSP, and if $\mathrm{M}$-current inhibition is the primary effect of TLHRH action, then the M-current should be inhibited during the late, slow EPSP. Figure 9 shows that this is the case. In the same cell, pressure application of $\mathrm{T}$ LHRH gave a similar response (fast records shown in Fig. 6A). Additionally, the LHRH antagonist speeded recovery of the M-current inhibition underlying the late, slow EPSP in this cell. Effects of the antagonist on the amplitude or kinetics of the late, slow EPSP were observed in some but not all cells; the negative results may simply be due to poor penetration of pressure-applied drugs into untrypsinized ganglia.

In some cells, the late, slow EPSP induced an additional inward current associated with an increased conductance, in addition to M-current inhibition. In a limited number of cells where both T-LHRH effects and the late, slow EPSP were examined, the additional inward current was generally present either for both responses or for neither. Unfortunately, this is not conclusive evidence that T-LHRH is the natural transmitter for the late, slow EPSP, as we (and others; Nishi et al., 1980; Kuffler and Sejnowski, 1983) have found a similar correlation for other agents that inhibit the M-current, such as substance $\mathbf{P}$ and muscarinic agonists. On the other hand, we would not expect a perfect correlation between the effects of T-LHRH and the late, slow EPSP in any case, as a cell that shows only M-current inhibition at one dose may show the additional inward current at higher concentrations.

\section{Discussion}

T-LHRH is a potent inhibitor of the M-current of bullfrog sympathetic ganglion cells and also in some cells induces an additional inward current. Its action, like that of M-LHRH, appears to be mediated by a receptor similar to the LHRH receptor of rat pituitary cells (Jan et al., 1980). However, T-LHRH is significantly more po- 

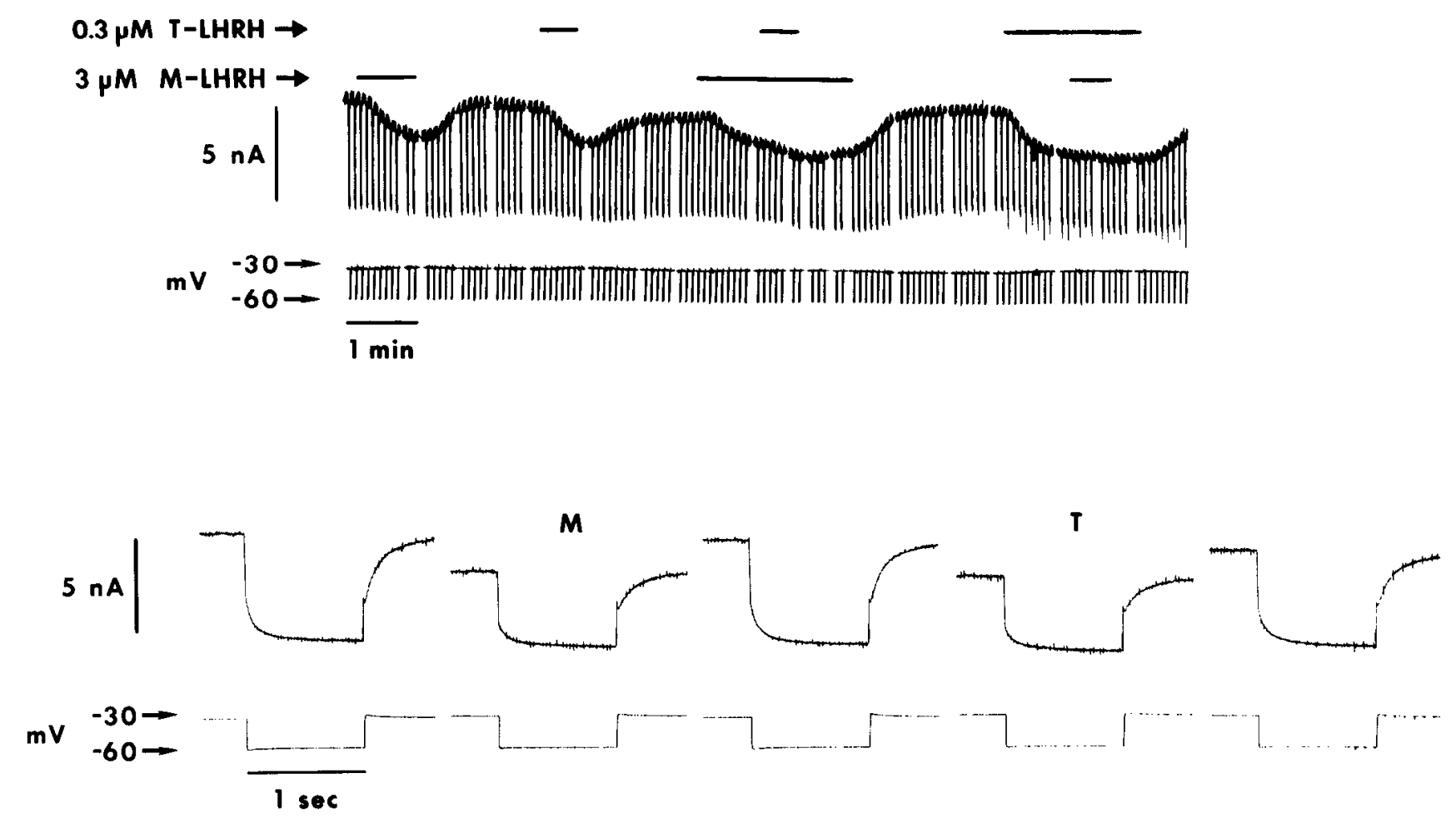

M

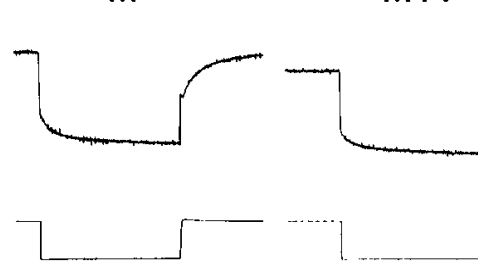

M

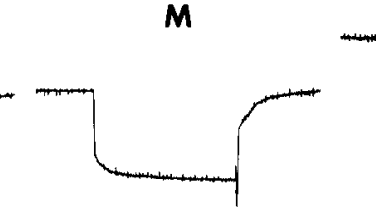

T

$T+M$

Figure 4. Comparison of T-LHRH with M-LHRH on a bullfrog ganglion neuron. The horizontal bars in the top record mark applications of T-LHRH $(0.3 \mu \mathrm{M}$, at $20 \mathrm{psi})$ or M-LHRH ( $3 \mu \mathrm{M}$, bath application). The cell was abruptly lost during recovery from the last response shown. The bottom rows show selected fast records before, during, and after the responses. M, M-LHRH; T, T-LHRH. In the first two responses, the M-current was inhibited $44 \%$ by T-LHRH and $49 \%$ by M-LHRH. Bath application of $0.3 \mu \mathrm{M}$ T-LHRH inhibited $65 \%$ of the M-current in the same cell (not shown).

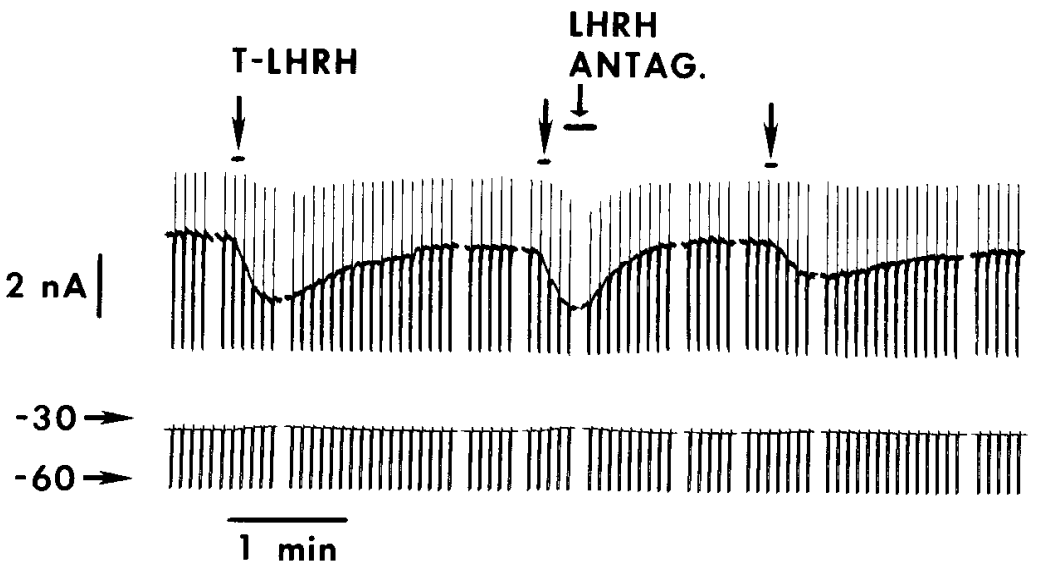

Figure 5. Effect of [D-pGlu $\left.{ }^{1}, \mathrm{D}-\mathrm{Phe}^{2}, \mathrm{D}-\mathrm{Trp}^{3,6}\right] \mathrm{M}-\mathrm{LHRH}$ on the action of TLHRH on a bullfrog ganglion neuron. T-LHRH $(10 \mu \mathrm{M})$ was applied three times, for 5 sec at 5 psi, at the longer arrows. [D-pGlu $\left.{ }^{1}, \mathrm{D}-\mathrm{Phe}^{2}, \mathrm{D}-\mathrm{Tr}^{3,6}\right] \mathrm{M}$ LHRH $(100 \mu \mathrm{M})$; (LHRH Antag.) was applied for 15 sec where marked, from a different barrel of a three-barrel pressure pipette. 


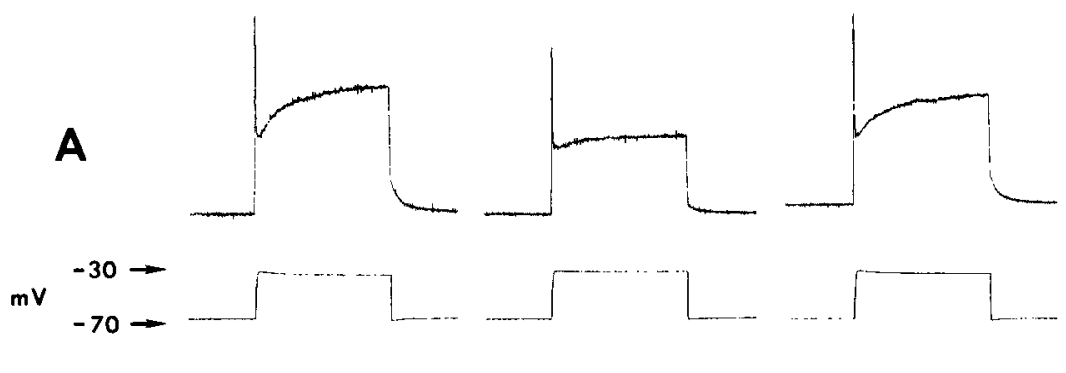

T-LHRH
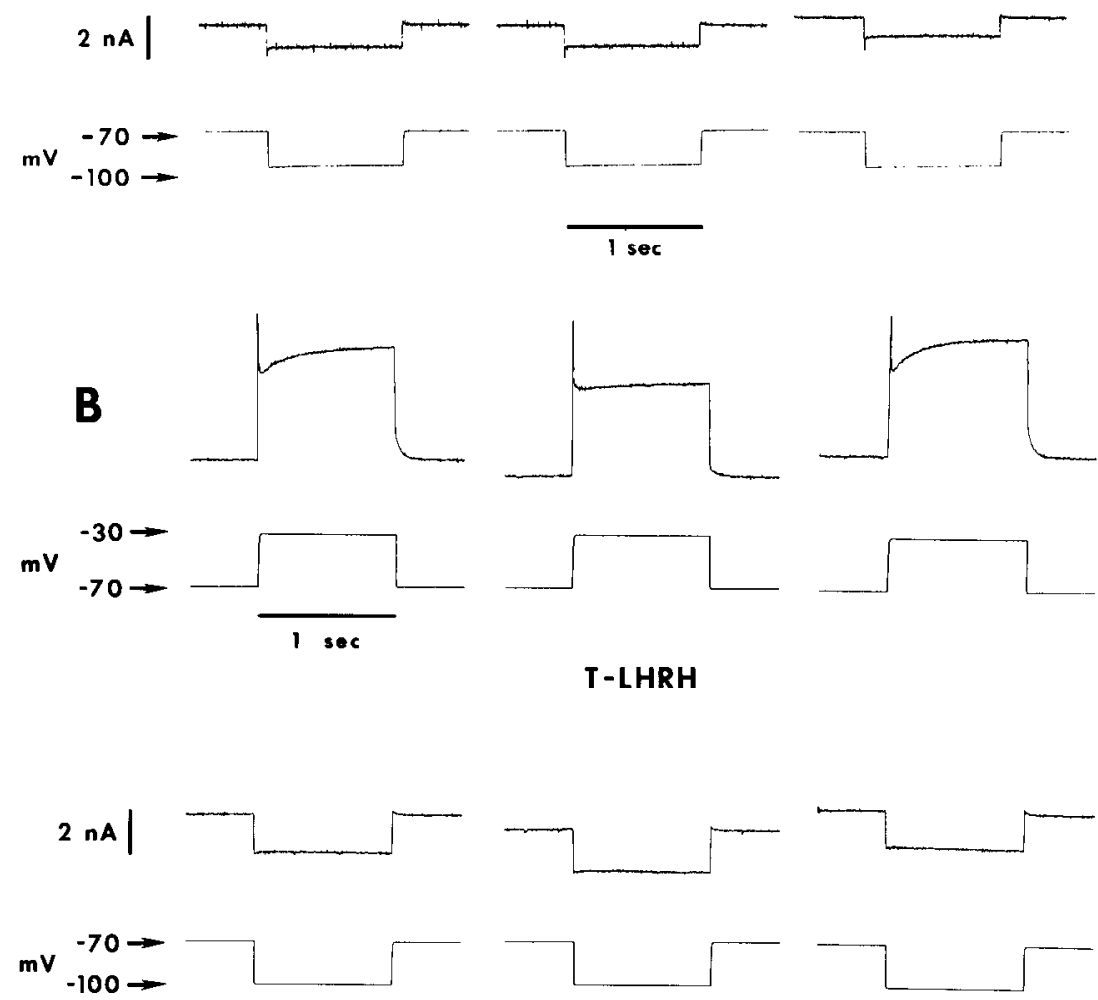

Figure 6. Effects of T-LHRH at more hyperpolarized potentials. Cells were clamped at -60 to $-70 \mathrm{mV}$ and were stepped alternately positive or negative to the voltages shown. For each response, fast records of the response to depolarizing sleps (lop) and hyperpolarizing steps (bottom) are shown before (left), during (middle), and after (right) the response. Both cells were from ganglia that had not been treated with trypsin. $A$, Response to a 30 -sec application of $25 \mu \mathrm{M}$ T-LHRH at 50 psi. These records are from the response to T-LHRH illustrated at a slow time scale in Figure 9. The ganglion was in Ringer's solution containing $4 \mathrm{mM} \mathrm{CaCl}$, no $\mathrm{MgCl}_{2}, 2 \mu \mathrm{M}$ atropine, and $20 \mu \mathrm{M}$ $d$-tubocurarine. $B$, Response of a cell (in usual Ringer's solution) to a 30 -sec application of $10 \mu \mathrm{M}$ T-LHRH at 5 psi.

tent than M-LHRH on the bullfrog ganglion, which is not the case on rat pituitary cells in culture (Eiden et al., 1982; W. Vale, personal communication). This helps explain the puzzling observation that micromolar concentrations of M-LHRH are required for action on bullfrog neurons, in contrast to its nanomolar potency on pituitary cells. Our $\mathrm{I}_{50}$ of $0.35 \mu \mathrm{M}$ for T-LHRH may still underestimate its potency, if proteolysis occurs during application of exogenous peptides to the ganglion. It is also possible that desensitization occurs during the pro- longed exposure to T-LHRH, although we did not observe recovery of M-current during continued application.

Another analogue of M-LHRH, which may be [Gln $\left.{ }^{8}\right]$ $\mathrm{M}-\mathrm{LHRH}$, has been reported to be the LHRH for the chicken (Miyamoto et al., 1982; King and Millar, 1982a, b). Chicken LHRH is not likely to be the LHRH-like transmitter of bullfrog ganglia, as it is separable from the major LHRH-like component of bullfrog ganglia (Eiden et al., 1982), and we have preliminary evidence 

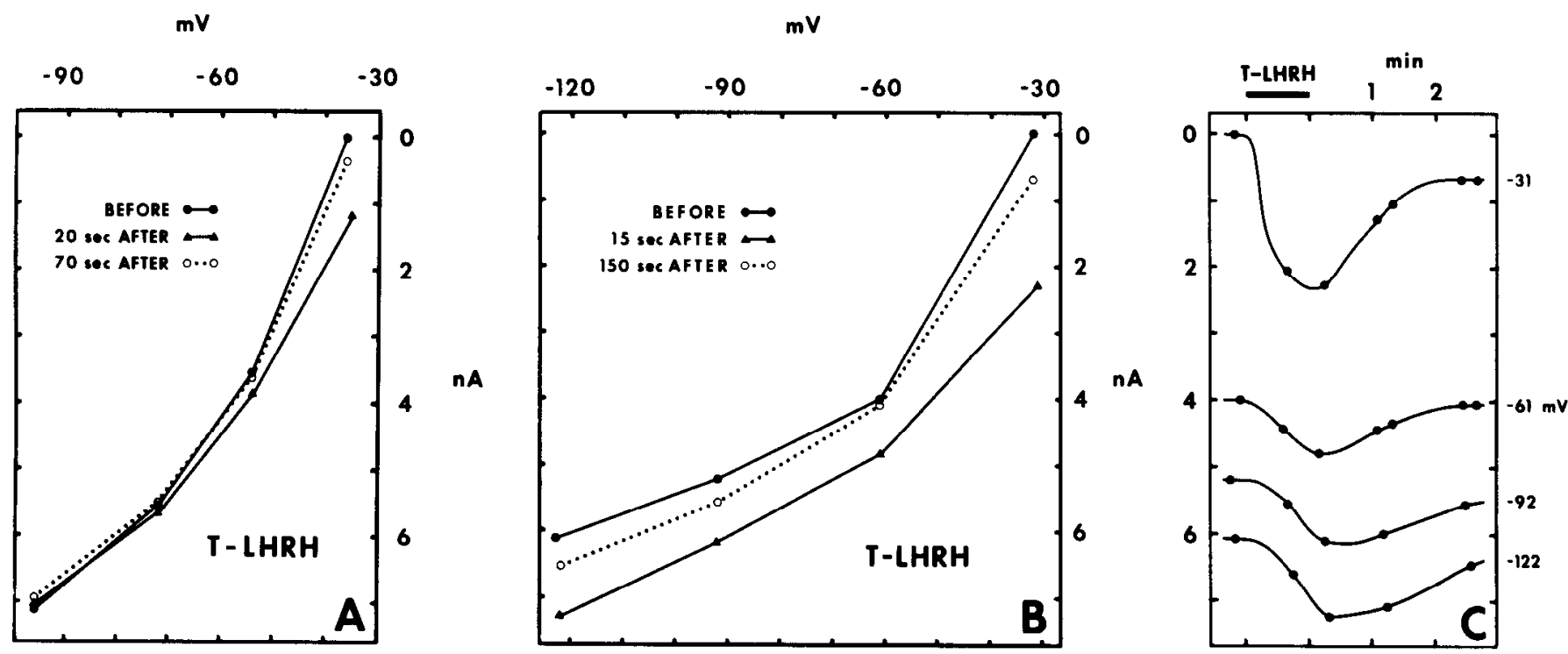

Figure 7. Effects of T-LHRH on steady-state current-voltage curves of bullfrog ganglion neurons. Cells were held at -30 to $-36 \mathrm{mV}$, with steps to the voltages shown. Only a few voltage levels were examined for each response, to allow current-voltage curves to be obtained at different stages during the response. $A$, T-LHRH $(10 \mu \mathrm{M})$ was applied for 30 sec at 5 psi. The upward curvature (rectification) in these curves, which is reduced by T-LHRH, is due to the M-current (Adams et al., 1982a). $B$, TLHRH $(10 \mu \mathrm{M})$ was applied to a cell in a trypsinized ganglion for $60 \mathrm{sec}$ at 5 psi. Not only was the M-current inhibited (inward current at $-30 \mathrm{mV}$, as in Fig. $7 \mathrm{~A}$ ), but also there was inward current even at $-122 \mathrm{mV}$. The time course of this response is shown in $C$, as the steady-state currents from 1-sec steps to the potentials given at the right of the graph (and at the holding potential of $-31 \mathrm{mV}$ ). Note that the effect at $-31 \mathrm{mV}$, reflecting primarily M-current inhibition, is more rapid in onset and recovery than the effect at -92 or $-122 \mathrm{mV}$.

that $\left[\mathrm{Gln}^{8}\right] \mathrm{M}-\mathrm{LHRH}$ is much less potent than T-LHRH on the M-current of bullfrog sympathetic neurons.

These results, combined with the biochemical and immunological resemblance of T-LHRH and an endogenous peptide from bullfrog ganglia (Eiden et al., 1982), suggest that T-LHRH is the endogenous LHRH-like peptide responsible for the late, slow EPSP in bullfrog sympathetic ganglia. Definitive proof will only come with sequencing of the bullfrog ganglion peptide.

One difficulty that we encountered in establishing the existence of an additional inward current induced by TLHRH is that the effect is, operationally, simply an increase in the leak conductance of the cell. Such an increase is often seen either spontaneously, or in an artifactual way by changing the flow through the bath, or other factors that might disturb the impalement of the cell by the microelectrode. We became convinced of the reality of the inward current as a drug effect by (1) the reversibility of the effect (which was observed in many but not all cases, probably due to the slowness of the effect), (2) reversal of the additional inward current by an LHRH antagonist (Fig. 8), and (3) the difference in time course between $M$-current inhibition and the additional inward current. This observation also shows that the inward current at $-60 \mathrm{mV}$ is not due to inhibition of residual M-current at that potential in some cells. The difference in time course between inhibition of $\mathrm{M}$ current and induction of the additional inward current was also noted (for M-LHRH) by Katayama and Nishi (1982).

We are not prepared to give an estimate of the fraction of the cells in the bullfrog sympathetic ganglion that show an additional inward current to T-LHRH. First, many cells that do not show such a response in a given test might well do so if higher concentrations (or longer durations of application) were used. Second, although we see both types of cell in both trypsinized and untrypsinized ganglia, there may be quantitative differences in the frequency. Third, if the current is activated by hyperpolarization, as suggested by Katayama and Nishi (1982) and by the data of Jan et al. (1980), our paradigm of holding at relatively positive potentials with brief hyperpolarizing steps may underestimate the maximal amplitude of the current.

Katayama and Nishi (1982) and Kuffler and Sejnowski (1983) have also examined the late, slow EPSP (and effects of M-LHRH) under voltage clamp. Both groups have reported that some cells show only a decrease in conductance, presumably to potassium (type I response of Katayama and Nishi, 1982), whereas other cells show only a conductance increase (type II) or a mixed response. Katayama and Nishi (1982) also conclude that the type II response is due to an increase in conductance to sodium. We have demonstrated directly that the Mcurrent is inhibited during the late, slow EPSP, and by exogenous T-LHRH. This effect probably corresponds to the type I response. Our additional inward current is similar to their type II response. We have not observed an LHRH-induced inward current without inhibition of the M-current (a pure type II response), and in fact the additional current appears to be associated with responses where the M-current is inhibited most fully. However, Katayama and Nishi (1982) observed a pure type II response only in $8 \%$ of their cells, and only in 


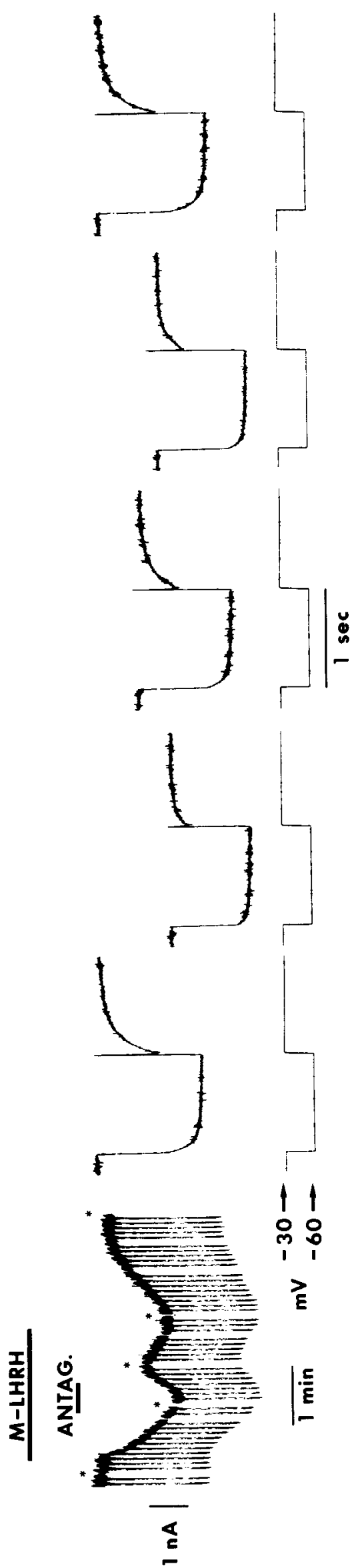

cells where no M-current is present. In our hands, essentially all healthy cells have M-currents when held in the appropriate voltage range (positive to $-60 \mathrm{mV}$ ).

Kuffler (1980), Kuffler and Sejnowski (1983), and Katayama and Nishi (1982) have reported that the inward current induced by LHRH occasionally reverses to an outward current at hyperpolarized potentials, which is not expected either from an M-current inhibition or from an increased conductance to sodium. We have not observed this effect with our protocol of 1-sec hyperpolarizing steps from holding potentials of -30 to $-70 \mathrm{mV}$.

The M-current of bullfrog sympathetic ganglia is also inhibited by muscarinic agonists (Brown and Adams, 1980; Adams et al., 1982b), and during the cholinergic slow EPSP (Adams and Brown, 1982). As for LHRH, this muscarinic effect is also sometimes accompanied by an additional inward current (Kuba and Koketsu, 1976; Adams et al., 1982b), and variability in this effect has led to considerable confusion in the literature. Substance $\mathrm{P}$, which depolarizes bullfrog ganglion neurons (Nishi et al., 1980; Jan and Jan, 1982), also inhibits the M-current (Adams et al., 1983) and at high concentrations induces an additional, slowly developing inward current with increased conductance (S. W. Jones and P. R. Adams, unpublished findings). This association may be indicative of a common intracellular pathway for M-current inhibition and the additional current by these different agents, which act via different receptors (Jan and Jan, 1982; Adams et al., 1982b). If both effects are due to the same (as yet unidentified) second messenger, it is interesting that the time and concentration dependence of the two effects are different.

Association of $\mathrm{M}$-current inhibition and additional inward current may not be unique to bullfrog ganglion neurons. Substance $\mathrm{P}$ has been reported to have similar effects on guinea pig inferior mesenteric ganglion neurons (Minota et al., 1981). Hashiguchi et al. (1982) have reported that muscarine decreases the $M$-current and also induces an inward current without change in conductance in rabbit superior cervical ganglion. The increase in conductance associated with the additional inward current in bullfrog cells is quite small (Fig. $6 B$; see also Katayama and Nishi, 1982), and since that current is observed only at hyperpolarized potentials far from its reversal potential (if it is a sodium current), a change in the slope of a current-voltage curve might not be detectable.

The relative importance of $\mathrm{M}$-current inhibition and of induction of additional inward current in the slow effects of peptides and muscarinic agonists remains to be evaluated. However, it should be noted that M-current inhibition can have a more profound effect on the properties of a neuron. Normally, bullfrog ganglion neurons are simple, one-to-one relays, but $\mathbf{M}$-current inhibition can allow repetitive firing to single stimuli (Adams et al., 1982b). A tonic increase in sodium conductance would presumably only add to the already suprathreshold effect of the large nicotinic EPSPs in these cells. Furthermore, the M-current inhibition is the dominant effect in the range between rest and threshold in these cells, and is therefore more likely to come into play under physiological conditions. 

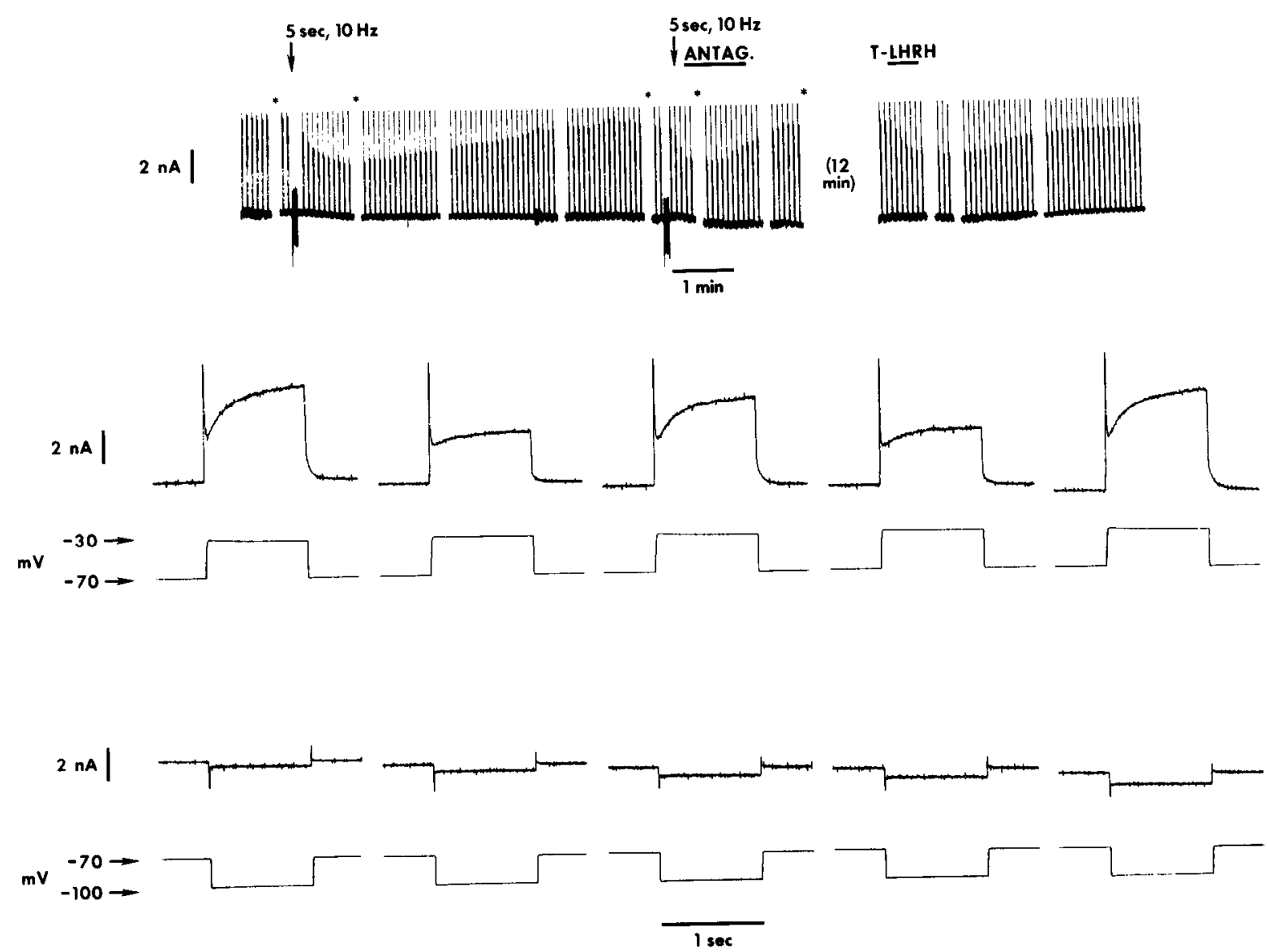

Figure 9. Inhibition of M-current during the late, slow EPSP. Top, Current records for steps from -70 to $-32 \mathrm{mV}$, showing the time course of the response to a train of preganglionic stimuli or to T-LHRH. During the time marked by the bar labeled ANTAG., $25 \mu \mathrm{M}$ [D-pGlu $\left.{ }^{1}, \mathrm{D}-\mathrm{Phe}^{2}, \mathrm{D}-\mathrm{Trp}^{3,6}\right] \mathrm{M}$-LHRH was applied at $50 \mathrm{psi}$. The T-LHRH response was to $25 \mu \mathrm{M}$ at $50 \mathrm{psi}$ for 30 sec, also marked by a horizontal bar. An inward drift of $2 \mathrm{nA}$ during the 12 min preceding the T-LHRH response is not shown. Bottom, Fast records of currents during voltage steps at the times marked by asterisks during the late, slow EPSCs. In addition to clear inhibition of M-current visible in the steps to $-32 \mathrm{mV}$, there was a slow inward current and increase in the leak conductance shown by steps to $-96 \mathrm{mV}$. As it did not recover even after antagonist application, it is presumably not a specific effect. Fast records of the response to T-LHRH are given in Figure $6 A$. The ganglion was in Ringer's solution containing 4 mM $\mathrm{CaCl}_{2}$, no $\mathrm{MgCl}_{2}, 1 \mu \mathrm{M}$ atropine, and $20 \mu \mathrm{M} d$-tubocurarine.

\section{References}

Adams, P. R., and D. A. Brown (1980) Luteinizing hormonereleasing factor and muscarinic agonists act on the same voltage-sensitive $\mathrm{K}^{+}$-current in bullfrog sympathetic neurones. Br. J. Pharmacol. 68: 353-355.

Adams, P. R., and D. A. Brown (1982) Synaptic inhibition of the M-current: Slow excitatory post-synaptic potential mechanism in bullfrog sympathetic neurones. J. Physiol. (Lond.) 332: $263-272$.

Adams, P. R., D. A. Brown, and A. Constanti (1982a) Mcurrents and other potassium currents in bullfrog sympathetic neurones. J. Physiol. (Lond.) 330: 537-572.

Adams, P. R., D. A. Brown, and A. Constanti (1982b) Pharmacological inhibition of the M-current. J. Physiol. (Lond.) 332: 223-262.

Adams, P. R., D. A. Brown, and S. W. Jones (1983) Substance $\mathrm{P}$ inhibits the $\mathrm{M}$-current in bullfrog sympathetic neurones. Br. J. Pharmacol. 79: 330-333.

Brown, D. A., and P. R. Adams (1980) Muscarinic suppression of a novel voltage-sensitive $\mathrm{K}^{+}$-current in a vertebrate neurone. Nature 283: 673-676.

Choi, D. W., and G. D. Fischbach (1981) GABA conductance of chick spinal cord and dorsal root ganglion neurons in cell culture. J. Neurophysiol. 45: 605-620.

Eiden, L. E., and R. L. Eskay (1980) Characterization of LRFlike immunoreactivity in the frog sympathetic ganglia: Nonidentity with LRF decapeptide. Neuropeptides 1: 29-37.

Eiden, L. E., E. Loumaye, N. Sherwood, and R. L. Eskay (1982) Two chemically and immunologically distinct forms of luteinizing hormone-releasing hormone are differentially expressed in frog neural tissues. Peptides 3: 323-327.

Galvan, M., and P. R. Adams (1982) Control of calcium current in rat sympathetic neurons by norepinephrine. Brain Res. 244: 135-144.

Hashiguchi, T., H. Kobayashi, T. Tosaka, and B. Libet (1982) Two muscarinic depolarizing mechanisms in mammalian sympathetic neurons. Brain Res. 242: 378-382.

Hökfelt, T., O. Johansson, A. Ljungdahl, J. M. Lundberg, and M. Schultzberg (1980) Peptidergic neurones. Nature 284: 515-521.

Jan, L. Y., and Y. N. Jan (1982) Peptidergic transmission in sympathetic ganglia of the frog. J. Physiol. (Lond.) 327: 219246.

Jan, Y. N., L. Y. Jan, and S. W. Kuffler (1979) A peptide as a possible transmitter in sympathetic ganglia of the frog. Proc. 
Natl. Acad. Sci. U. S. A. 76: 1501-1505.

Jan, Y. N., L. Y. Jan, and S. W. Kuffler (1980) Further evidence for peptidergic transmission in sympathetic ganglia. Proc. Natl. Acad. Sci. U. S. A. 77: 5008-5012.

Katayama, Y., and S. Nishi (1977) The ionic mechanism of the late slow EPSP in amphibian sympathetic ganglion cells. Proc. Int. Union Physiol. Sci. 13: 371.

Katayama, Y., and S. Nishi (1982) Voltage-clamp analysis of peptidergic slow depolarizations in bullfrog sympathetic ganglion cells. J. Physiol. (Lond.) 333: 305-313.

Kelly, J. S. (1982) Electrophysiology of peptides in the central nervous system. Br. Med. Bull. 38: 283-290.

King, J. A., and R. P. Millar (1982a) Structure of chicken hypothalamic luteinizing hormone-releasing hormone. I. Structural determination on partially purified material. J. Biol. Chem. 257: 10722-10728.

King, J. A., and R. P. Millar (1982b) Structure of chicken hypothalamic luteinizing hormone-releasing hormone. II. Isolation and characterization. J. Biol. Chem. 257: 1072910732.

Kuba, K., and K. Koketsu (1976) Analysis of the slow excitatory postsynaptic potential in bullfrog sympathetic ganglion cells. Jpn. J. Physiol. 26: 651-669.

Kuffler, S. W. (1980) Slow synaptic responses in autonomic ganglia and the pursuit of a peptidergic transmitter. J. Exp. Biol. 89: 257-286.

Kuffler, S. W., and T. J. Sejnowski (1983) Peptidergic and muscarinic excitation at amphibian sympathetic synapses. J.
Physiol. (Lond.) 341: 257-278.

Minota, S., N. J. Dun, and A. G. Karczmar (1981) Substance $P$-induced depolarization in sympathetic neurons: Not simple $\mathrm{K}^{+}$inactivation. Brain Res. 216: 224-228.

Miyamoto, K., Y. Hasegawa, T. Minegishi, M. Nomura, Y. Takahashi, M. Igarashi, K. Kanagawa, and H. Matsuo (1982) Isolation and characterization of chicken hypothalamic luteinizing hormone-releasing hormone. Biochem. Biophys. Res. Commun. 107: 820-827.

Nishi, S., Y. Katayama, J. Nakamura, and H. Ushijima (1980) A candidate substance for the chemical transmitter mediating the late slow EPSP in bullfrog sympathetic ganglia. Biomed. Res. 1 (suppl.): 144-148.

North, R. A., and T. M. Egan (1982) Electrophysiology of peptides in the peripheral nervous system. Br. Med. Bull. 38: 291-296.

Rivier, J. E., and W. W. Vale (1978) [D-pGlu',D-Phe ${ }^{2}, \mathrm{D}-\mathrm{Trp}^{3,6}$ ] LRF. A potent luteinizing hormone releasing factor antagonist in vitro and inhibitor of ovulation in the rat. Life Sci. 23: 869-876.

Sejnowski, T. J. (1982) Peptidergic synaptic transmission in sympathetic ganglia. Fed. Proc. 41: 2923-2928.

Sherwood, N., L. Eiden, M. Brownstein, J. Spiess, J. Rivier, and W. Vale (1983) Characterization of a teleost gonadotropin-releasing hormone. Proc. Natl. Acad. Sci. U. S. A. 80: 2794-2798.

Wilson, W. A., and M. M. Goldner (1975) Voltage clamping with a single microelectrode. J. Neurobiol. 6: 411-422. 